\title{
A MODIFIED TONGUE COATING INDEX
}

\author{
Anna Nenova-Nogalcheva ${ }^{1}$, Desislava Konstantinova ${ }^{2}$, Kamen Nogalchev ${ }^{2}$ \\ ${ }^{1}$ Department of Oral Surgery, Faculty of Dental Medicine, Medical University of Varna \\ ${ }^{2}$ Department of Prosthetic Dentistry, Faculty of Dental Medicine, \\ Medical University of Varna
}

\begin{abstract}
Tongue coating is an essential predictor of a number of systemic diseases of bed-ridden patients. Their general status puts limitations on the diagnostic facilities and calls for the use of an easily applicable tongue coating criteria/index. The authors' objective was to propose a modified index for the extent of tongue coating based on a conventional method study performed on bed-ridden chronic kidney disease (CKD) patients and CKD patients undergoing regular renal treatment. The units of observation were 70 patients, aged $60 \pm 28.5$ years. All patients underwent thorough extra- and intraoral examinations. Tongue coating was tested by two methods: using the Tongue Coating Index as per Kojima et al. (1985), and using the authors' modified index. The data analysis showed that coating of varying degrees was observed in $100 \%$ of patients. The chi-square test of independence (incorporating Yates's correction for continuity) revealed that there was not a statistically significant correlation between the extent of tongue coating and patients' gen$\operatorname{der}\left(\chi^{2}(\mathrm{df}=1, \mathrm{n}=70)=\mathbf{0 . 8 2 6}, \mathrm{p}=\mathbf{0 . 3 6}\right)$, however, there was a dependency on patients' age. The second set of tests based on the proposed index matched the results of the first examination using Kojima's Index. The $\chi 2$ test of independence proved a strong statistically significant correlation between the two indices ( $\chi 2$ ( $d f=3$, $\mathrm{n}=70)=44.877, \mathrm{p}<0.01$, Kendall's coefficient $($ tau-b $)=0.714$, Spearman's coefficient $=0.772)$. Conclusion: The modified Tongue Coating Index is easily accessible and applicable in common dental practices.
\end{abstract}

Keywords: CKD, modified index, tongue coating

\section{INTRODUCTION}

Tongue coating is an indication for the development of a disease process or the result of some form of treatment. Scientific literature lists numerous reports on the objective study of tongue coating in various groups of patients $(1,2,3)$. Those studies involve

Address for correspondence:

Anna Nenova-Nogalcheva

Department of Oral and Maxillofacial Surgery,

Faculty of Dental Medicine,

Medical University of Varna

84 Tzar Osvoboditel Blvd.

9000 Varna, Bulgaria

e-mail:anenova@yahoo.com

Received: April 30, 2017

Accepted: May 12, 2017 the use of specialized equipment which requires certain manipulation time. Xingzheng et al. developed a novel imaging system, recording human tongue information precisely for medical analysis, while Kim et al. applied a digital tongue imaging system (DTIS), which measured the percentages of tongue coating on the tongue surface $(4,5)$.

As tongue coating is a clinical symptom and can only assist in the diagnosis of common diseases or in the detection of a pathogenetic mechanism of ongoing processes, it is often measured only by a conventional method, i.e. examining the dorsal surface of the tongue (6). This method is more easily accessible and less time-consuming, hence being applicable in common clinical practice (6). 
AIM

The authors' objective was to propose a modified index for the extent of tongue coating based on a conventional method study performed on bed-ridden chronic kidney disease (CKD) patients and CKD patients undergoing regular renal treatment.

\section{MATERIALS AND METHODS}

The units of observation were 70 patients $(37 \mathrm{fe}$ male and 33 male patients) on chronic dialysis treatment aged $60 \pm 28.5$ years (with the youngest participant being 32 years old and the oldest - 89 years old). All participants signed an informed consent form after being informed in detail of the purpose and terms of participation in the study.

The patients underwent extra- and intraoral examinations. The objective findings were gathered through visual inspection of the dorsum of the tongue in a protruded position and were recorded using photo-documentation assessed by the Index of Kojima et al. (1985) (7) as well as a modified index assessing the location of the coating rather than its thickness and color. The scores according to the Index of Kojima are listed below:

$\diamond 0$ - no coating (visual)

$\diamond 1-$ a thin coating of less than one third of the back of the tongue

$\diamond 2$ - a thin coating of less than two thirds of the tongue or less than $1 / 3$ covered with a thick coating

$\diamond 3$ - more than two thirds covered with a thin tongue coating or less than $2 / 3$ covered with a thick tongue coating

$\diamond 4$ - more than two thirds of the tongue is covered with a thick coating

The statistical analysis of data was performed using SPSS Statistics software package for epidemiological and clinical research (V.16.00, Nov. 2007).

\section{RESULTS AND DISCUSSION}

The data analysis showed that coating of varying degrees was observed in $100 \%$ of patients. The variations proved to be in terms of its distribution across the dimensions of the tongue surface area. According to the Index of Kojima the following percentage distributions were observed (Figure 1):

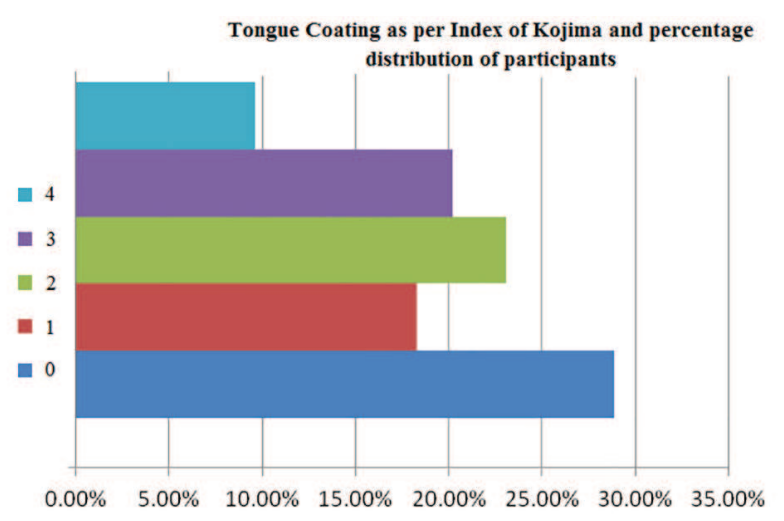

Fig. 1. Percentage distribution of participants according to the Tongue Coating Index of Kojima.

The results of the $\chi 2$ independence test (incorporating Yates' correction for continuity) showed that there was no statistically significant correlation between the extent of tongue coating and patients' gender $\left(\chi^{2}(\mathrm{df}=1, \mathrm{n}=70)=0.826, \mathrm{p}=0.36\right)$, which overrode the need to assess tongue coating according to participants' gender.

The observations revealed the presence of a strong statistically significant correlation between the extent of tongue coating and the patients' age, as the patients were divided into two groups: up to 60 years of age and over 60 years, with an average age of $60 \pm 28.5$ years. $\left(\chi^{2}(\mathrm{df}=1, \mathrm{n}=70)=41.065, \mathrm{p}<0.01\right.$, $\mathrm{phi}=0.795, \mathrm{p}<0.01)$. All patients up to 60 years of age (31 persons) exhibited a low extent of tongue coating (scores $0,1,2$ ), whereas $79.5 \%$ of patients (31 persons) over 60 years of age had a high degree (scores 3 or 4 ) of tongue coating. Only $20.5 \%$ of the patients ( 8 persons) over 60 years of age showed a low extent of the condition (Figure 2).

The patients were grouped and examined using the modified index according to the location of the coating on the dorsum of the tongue, without taking into consideration its color and thickness. The second set of tests based on the proposed index matched the results of the measurements performed using Kojima's Index.

The percentage distribution of participants according to the extent of tongue coating fully overlapped the findings from the Kojima Index. The patients who scored 4 on the modified index constituted the largest percentage (31.51\%), corresponding to score 3 as per Kojima Index. Score 3 of tongue coat- 

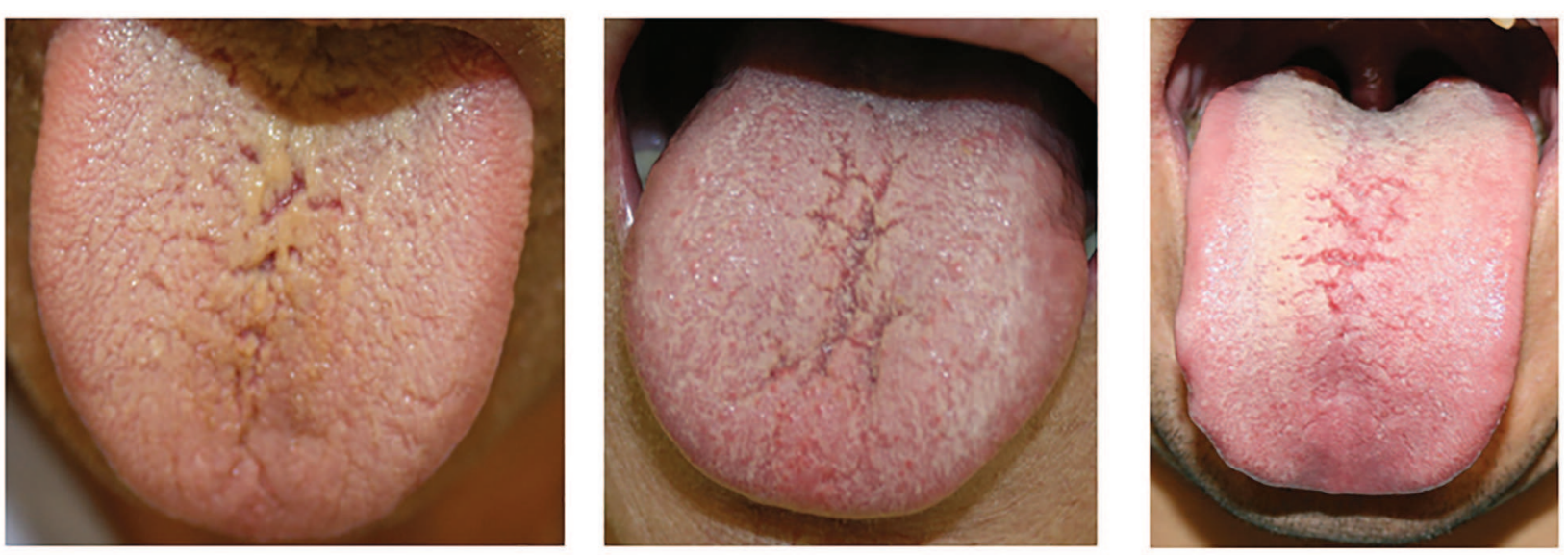

Fig. 2. Extent of tongue coating

ing according to the modified index, corresponding to score 2 on the Kojima Index, was observed in $31.03 \%$ of the patients. The patients exhibiting score 5 by the modified index, relevant to score 4 as per the Kojima Index, were $21.37 \%$.

There were no statistical dependencies between the extent of tongue coating established by the modified index and the participants' gender. The same results were observed from the cross tabulation of data on the correlation between the different scores of tongue coating and patients' age (up to 60 and over 60 years) (Table 1$)$.

\section{CONCLUSION}

In common clinical practice, tongue coating is perceived as a diagnostic and prognostic marker for the disease process. Therefore, it is necessary to use it as early as the first screening and later on in monitoring the progression of the disease and the consequences of its treatment. The tongue coating indices available are rather time-consuming and require certain manipulation time as well as a specific set of tools. The modified tongue coating index is easily accessible and applicable in common dental practices. It allows effortless reading of the findings from the

Table 1. Cross tabulation of data on the correlation between the extent of tongue coating, established by the modified index, and patients' age.

\begin{tabular}{|c|c|c|c|c|c|}
\hline \multirow[b]{2}{*}{ SCORES } & & & \multicolumn{2}{|c|}{ Age groups } & \multirow[b]{2}{*}{ Total } \\
\hline & & & $\begin{array}{l}\text { Up to } 60 \\
\text { years }\end{array}$ & $\begin{array}{c}\text { Over to } 60 \\
\text { years }\end{array}$ & \\
\hline \multirow{6}{*}{$\begin{array}{l}\text { Extent of } \\
\text { tounge coating }\end{array}$} & & Count $\%$ within row extent of tounge coating & 31 & 8 & 39 \\
\hline & $1,2,3$ & \%within colomn & $79.50 \%$ & $20.50 \%$ & $100 \%$ \\
\hline & & Both groups & $100 \%$ & $20.50 \%$ & $55.70 \%$ \\
\hline & & Count $\%$ within row extent of tounge coating & 0 & 31 & 31 \\
\hline & 4,5 & $\%$ within colomn & & $100 \%$ & $100 \%$ \\
\hline & & Both groups & $0 \%$ & $79.50 \%$ & $44.30 \%$ \\
\hline \multirow{3}{*}{ Total } & & $\%$ within row extent of tounge coating & 31 & 39 & 70 \\
\hline & & \% within colomn & $44.30 \%$ & $55.70 \%$ & $100 \%$ \\
\hline & & Both groups & $100 \%$ & $100 \%$ & $100 \%$ \\
\hline
\end{tabular}

The $\chi 2$ test of independence proved a strong statistically significant correlation between the two indices $(\chi 2(\mathrm{df}=3, \mathrm{n}=70)=44.877, \mathrm{p}<0.01$, Kendall's coefficient (tau-b) $=0.714$, Spearman's coefficient $=0.772$ ). dorsum of the tongue. The results from the examination of the condition using both indices (Index of Kojima and the modified index) completely overlapped. A strong statistical correlation was observed between the data obtained using both indices (Kendall's co- 
Anna Nenova-Nogalcheva, Desislava Konstantinova, Kamen Nogalchev

Table 2. Modified index assessment criteria

\section{SCORE MODIFIED INDEX CRITERIA}

1

2

3

4

5
No tongue coating visible

Tongue coating on the dorsum of the tongue visible at the tongue root (Radix linguae), extending to 2 $\mathrm{mm}$ from the median line (Linea mediana linguae)

Tongue coating visible from the tongue root to the middle of the dorsum and extending to $3 \mathrm{~mm}$ from the median line

Tongue coating visible over the middle of the dorsum, extending to $4 \mathrm{~mm}$ from the median line

Tongue coating visible down to the tip of the tongue and extending to $4 \mathrm{~mm}$ from the median line

efficient tau- $b=0.714)$. The data led to the proposal of the following modified tongue coating index (Table 2).

\section{REFERENCES}

1. Kho HS, Lee SW, Chung SC, Kim YK. Oral manifestations and salivary flow rate, $\mathrm{pH}$, and buffer capacity in patients with end-stage renal disease undergoing hemodialysis. Oral Surg Oral Med Oral Pathol Oral Radiol Endod. 1999, 88(3): 316-319. doi: 10.1016/S1079-2104(99)70035-1

2. Alamo SM, Esteve CG, Sarrión Pérez MG. Dental considerations for the patient with renal disease. J Clin Exp Dent. 2011; 3(2): 112-9. doi: 10.4317/ jced.3.e112

3. Chi AC, Neville BW, Krayer JW, Gonsalves WC. Oral manifestations of systemic disease. Am Fam Physician. 2010 ;82(11):1381-8.

4. Wang X, Zhang D. A high quality color imaging system for computerized tongue image analysis. Expert Syst Appl. 2013; 40(15):5854-66. doi: 10.1016/j.eswa.2013.04.031

5. Kim J, Han GJ, Choi BH, Park JW, Park K. Yeo IK, et al. Development of differential criteria on tongue coating thickness in tongue diagnosis. Complement Ther Med. 2012 ;20(5):316-22. doi: 10.1016/j. ctim.2012.03.004

6. Kim J, Han G, Ko SJ, Nam DH, Park JW, Ryu B, et al. Tongue diagnosis system for quantitative assessment of tongue coating in patients with functional dyspepsia: a clinical trial. J Ethnopharmacol. 2014;155(1):709-13. doi: 10.1016/j.jep.2014.06.010

7. Kojima K. Clinical studies on the coated tongue. Japanese J Oral Maxilofac Sur. 1985; 31(7): 1659-78. doi: 10.5794/jjoms.31.1659

Scripta Scientifica Medicinae Dentalis, vol. 3, No 1, 2017, pp. 32-35 